\title{
ISO-Transliteration des Kyrillischen
}

\begin{tabular}{|c|c|c|c|}
\hline Russisch & Transliteration & Russisch & Transliteration \\
\hline $\mathrm{A} \mathrm{a}$ & $\mathrm{A} \mathrm{a}$ & $\mathrm{P} p$ & $\mathrm{R} \mathrm{r}$ \\
\hline Б б & $\mathrm{B} \mathrm{b}$ & $\mathrm{Cc}$ & $\mathrm{S} \mathrm{s}$ \\
\hline В в & $\mathrm{V}_{\mathrm{V}}$ & $\mathrm{T} \mathrm{T}$ & $\mathrm{T} \mathrm{t}$ \\
\hline$\Gamma \Gamma$ & $\mathrm{G} g$ & $\mathrm{Y} y$ & $\mathrm{U} \mathrm{u}$ \\
\hline Д д & $\mathrm{D} \mathrm{d}$ & $\Phi \phi$ & F f \\
\hline $\mathrm{E} \mathrm{e}$ & $\mathrm{E} \mathrm{e}$ & $\mathrm{Xx}$ & $\mathrm{Ch} \mathrm{ch}$ \\
\hline$\ddot{\mathrm{E}} \ddot{\mathrm{e}}$ & $\ddot{\mathrm{E}} \ddot{\mathrm{e}}$ & Ц ц & $\mathrm{C} \mathrm{c}_{\mathrm{r}}$ \\
\hline Ж ж & Ž ž & Ч ч & $\check{C} \check{c}$ \\
\hline $33_{3}$ & $\mathrm{Z}_{\mathrm{z}}$ & Ш ш & ŠS š \\
\hline И и & $\mathrm{I} \mathrm{i}$ & Щ щ & Š ̌́ $\check{S} \check{S} \check{c}$ \\
\hline Й й & $\mathrm{J} \mathrm{j}$ & $\mathbf{b}$ & , \\
\hline К к & $\mathrm{K} \mathrm{k}$ & Ы ы & Y y \\
\hline Л л & L 1 & b & , \\
\hline $\mathrm{M} \mathrm{M}$ & $\mathrm{Mm}$ & $Э э$ & $\dot{\mathrm{E}} \dot{\mathrm{e}}$ \\
\hline $\mathrm{H} \mathrm{H}_{\mathrm{H}}$ & $\mathrm{Nn}$ & Ю ю & $\mathrm{Ju}$ ju \\
\hline $\mathrm{O}$ o & $\mathrm{O}$ o & Я я & $\mathrm{Ja}$ ja \\
\hline$\Pi$ П & $\mathrm{Pp}$ & $\mathrm{b}$ & ě \\
\hline
\end{tabular}

